\title{
Alumni Profiles
}

\author{
Jonathan R. Nitschkea, Anna Quattropani ${ }^{b}$, Clémence Corminboeufc, Kelly Veloniad, \\ Kevin J. Wilkinson ${ }^{e}$, and Frank Kubel ${ }^{\dagger}$
}

\begin{abstract}
Former PhD students, post-docs and junior researchers of the Section de chimie et biochimie now holding positions at different universities and private companies remember the time they spent in Geneva and give an account of how this has set off and influenced their careers.
\end{abstract}

Keywords: Chemistry in Geneva

\section{Jonathan Nitschke, University of Cambridge, UK}

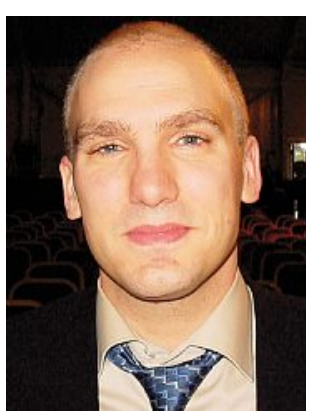

A passage to Geneva: It was chance, both in the senses of par hazard and bonne fortune, which led me away from the US and toward the University of Geneva. I had never really expected to leave my native land, but when Jean-Marie Lehn gave a talk at Berkeley near the end of my doctoral studies, I was amazed. I wanted to do that kind of chemistry. The US NSF was kind enough to pay my way to France, where I studied with Jean-Marie as a postdoc for two years. Near the end of my time in Strasbourg, I realized that my future lay elsewhere. I liked France, but it could be hard to get one's work done - if the guy who was supposed to do mass spectrometry felt like feeding the pigeons instead, quoi faire... I thus applied to several big US universities, getting one tenure-track job offer, as well as applying to an open position in the Organic Chemistry Department at Geneva, on a whim. I had never been to Switzerland, and I had never heard of a maitre-assistant. The interview went well; I

Correspondence: ${ }^{a}$ Dr. J. R. Nitschke

University Lecturer and Walters-Kundert Next-Generation Fellow

University of Cambridge, Department of Chemistry, UK ${ }^{b}$ Dr. A. Quattropani, Senior Scientist

Chemistry Department at Merck Serono, Geneva

'Prof. Dr. C. Corminboeuf

Ecole polytechnique fédérale de Lausanne, Switzerland

dProf. Dr. K. Velonia

Department of Material Science and Technology

University of Crete, Greece

eProf. Dr. K. J. Wilkinson

Department of Chemistry

University of Montreal, Canada

fProf. Dr. F. Kubel

TU Vienna, Austria

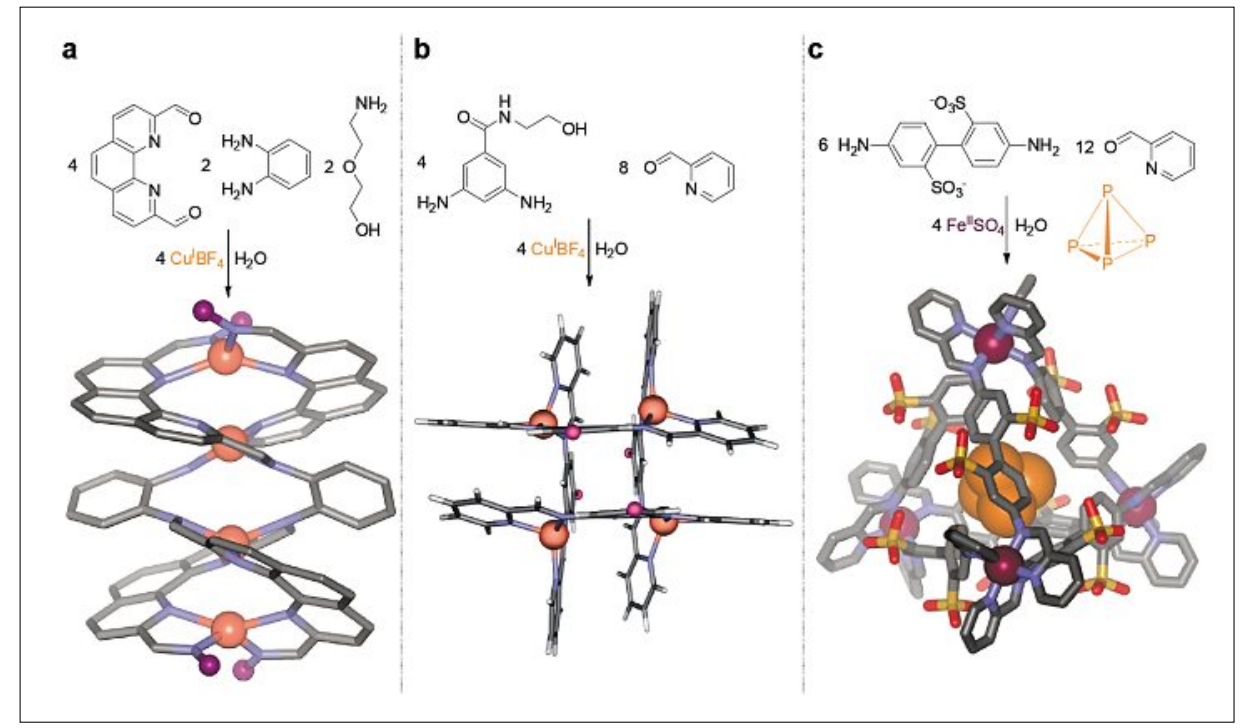

Fig. 1. Complex structures prepared from simple subcomponents: a) $\mathrm{Cu}_{4}^{\prime}$ helicate; ${ }^{[2]}$ b) $\mathrm{Cu}_{4}^{\prime}$ grid;;[3] c) $\mathrm{Fe}_{4}{ }_{4}$ tetrahedral cage. ${ }^{[4,5]}$

was promised full scientific independence and the opportunity to supervise two $\mathrm{PhD}$ students. In the end I chose Geneva because everything I needed was there, the teaching load was relatively light, and it seemed that I might stand a better chance of recruiting good students there. The senior members of the Department and School also impressed me; it seemed that good advice and mentoring would be available for the asking. These first impressions held up well with time.

The group's first two PhD students were hired from the Universite Louis Pasteur in Strasbourg, where there was no shortage of very well qualified MSc students in search of opportunity. I interviewed 15 and extended offers to the two best, David Schultz and Marie Hutin, who did not let me down. Their intelligence and hard work laid the foundations of the work that my group is carrying out today at the University of Cambridge. Just after concluding the interviews, I was called to Bern, where a senior chemistry professor interviewed me on the SNSF proposal that I had submitted. I did not make out so well as Marie and David, be- ing informed that the work that I proposed was much too ambitious - it would require the mastery of techniques and concepts to which I had never been exposed. "Write a new proposal," came the advice, "convince us that you can get good work done quickly with limited means."

Although this rejection was devastating, time has told that it was the best advice that I could have gotten at that point in my career, delivered in a context that I could not ignore. My senior colleagues came through with bridge funding so that I could still give Marie and David their promised places - a kindness for which I remain grateful - and the next proposal I wrote obtained modest SNSF funding.

This proposal, and the research programme that followed, involved the use of old chemistry - Daryle Busch's metaltemplated imine-bond forming reaction ${ }^{[1]}$ - in new ways. We called it subcomponent self-assembly to emphasize the use of simple precursors to build complex products. The preparations and crystal structures of three of these products are shown in Fig. 1. 
Each of these products was prepared simply by mixing the precursors shown in water, and each represents a different way to arrange four metal ions in space, going from a) one-dimensional linear array ${ }^{[2]}$ to b) two-dimensional grid ${ }^{[3]}$ to c) three-dimensional tetrahedron, ${ }^{[4]}$ which turned out to be capable of trapping white phosphorus $\left(\mathrm{P}_{4}\right)$ and rendering it air-stable as we recently reported in Science! ${ }^{[5]}$

Our work has led naturally into the investigation of complex systems of molecules, $\left.{ }^{6} 6\right]$ where reaction at one molecule may lead another to reassemble as signals cascade through a system. ${ }^{[7]}$ Such systems may thus serve as vehicles to explore fundamental questions of complexity and emergence, possibly allowing light to be shed upon the primordial moment when a collection of molecules first became alive, starting down the road of Darwinian evolution.

The University of Geneva thus turned out to be an excellent cradle and crucible for testing out new scientific ideas. Although Cambridge has turned out to be a superb environment as well - I would invite any young scientists whose imaginations are fired by our work to get in touch; perhaps you might join us! - part of me misses Switzerland very much, and longs to return.

[1] T. J. Hubin, D. H. Busch, Coord. Chem. Rev. 2000, $200,5$.

[2] D. Schultz, F. Biaso, L. Gagliardi, A. R. M. Shahi, C. J. Cramer, M. Geoffroy, J. R. Nitschke, Chem. Eur. J. 2008, 14, 7180.

[3] J. R. Nitschke, M. Hutin, G. Bernardinelli, Angew. Chem., Int. Ed. 2004, 43, 6724.

[4] P. Mal, D. Schultz, K. Beyeh, K. Rissanen, J. R. Nitschke, Angew. Chem., Int. Ed. 2008, 47, 8297.

[5] P. Mal, B. Breiner, K. Rissanen, J. R. Nitschke, Science 2009, 324, 1697

[6] R. J. Sarma, J. R. Nitschke, Angew. Chem., Int. Ed. 2008, 47, 377 .

[7] D. Schultz, J. R. Nitschke, Proc. Natl. Acad. Sci. USA 2005, 102, 11191.

\section{Anna Quattropani, Merck Serono, Geneva}

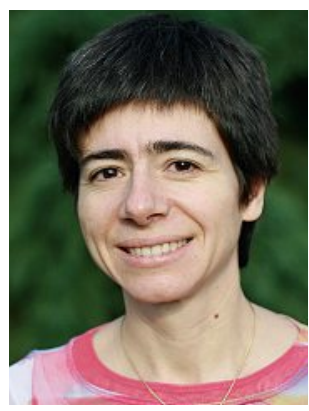

Looking back at the time I spent at the University of Geneva in the late eighties, I remember key experiences during my studies in chemistry that had an important impact in my future choices. First, I had to pass the legendary exam of Professors W. Oppolzer and $C$. $W$. Jefford, Organic Chemistry II, which concluded the license program. This exam was considered as the door to organic chemistry specialization, even though it was just covering the basics of this field. It was followed by the diploma program, which included three internships in research laboratories. These opportunities were my first research experiences and gave me the taste for it. With my interest for organic synthesis and the influence of transition metals on organic fragments, I selected my internships accordingly, starting with Prof. $A$. F. Williams, in the field of supramolecular chemistry. I was participating in a project on the formation of helical complexes of transition metals by self-assembly. The synthesis of a bis-bidentate ligand around two cobalt(II) ions resulted in the first triple helical compound to be reported. This work resulted in my first scientific publication (C. Piguet, G. Bernardinelli, B. Bocquet, A. Quattropani, A. F. Williams, J. Am. Chem. Soc. 2002, 114, 7440). For my second internship, I joined Prof. E. P. Kündig's group in the Organic Chemistry Department. Interestingly, for an organometallic group, my project concerned the synthesis of a chiral ligand by enzymatic resolution, a first experience with enzymes for me as well as for the group. I had the opportunity for my third internship to spend two months with Prof. O. R. Martin at SUNNY-University Center of Binghamton, NY (USA), in the field of carbohydrate chemistry, again a new aspect of organic chemistry.

With the project to combine organic chemistry and transition metals, I was accepted in the laboratories of Prof. E. P. Kündig to perform my diploma, followed by my PhD research between 1991 and 1996. With my diploma and PhD projects, I had opportunities to take advantage of the drastic electronic and steric influence of chromium tricarbonyl fragment on the reactivity of arene derivatives. A new approach of the asymmetric synthesis of arene chromium tricarbonyl complexes with chiral planarity was first developed, by enantioselective lithiation of prochiral complexes with chiral bases. The resulting planar chiral complex was then submitted to a sequential addition of a nucleophile and electrophile, followed by decomplexation, a transformation discovered in Prof. E. P. Kündig's laboratories. Further organic transformations yielded chiral alicyclic compounds, with a complete transfer of the planar chirality to the new stereogenic centres formed. This work illustrated the synthetic potential of planar chiral arene complexes in the synthesis of enantioenriched alicyclic systems (Anna Quattropani, PhD Thesis, University of Geneva, 1996). During these years, I had the great pleasure to have Prof. E. P. Kündig directing my thesis, teaching us the perseverance needed in research and how to pursue independently a scientific project.

I completed my academic experience in 1996 with a post-doctoral stay with Prof. L. E. Overman at the University of California, Irvine, funded by Swiss $\mathrm{Na}-$ tional Science Foundation, with the clear idea of reinforcing my skills in organic chemistry. I worked on solid-phase organic synthesis, a very popular field at that time. My project concerned the application of the aza-Cope-Mannich reaction on solidphase for the synthesis of a pyrrolidine library. Investigations in the laboratories of Prof. L. E. Overman over several years had demonstrated the merit of this reaction by the synthesis of complex alkaloids. Its transfer to solid phase allowed the parallel synthesis of an array of polysubstituted pyrrolidine derivatives, in comparable yields and stereoselectivity to solution phase. This post-doctoral experience was also an opportunity to discover a different and very inspiring scientific environment where I could further build my scientific knowledge.

With these diverse research experiences, in 1998, I came back to Switzerland, first for a position in the research group of Givaudan Roure in Dübendorf, working on fragrances and flavours. This job was followed the same year by a position in medicinal chemistry at Serono Pharmaceutical Research Institute in Geneva. Despite the huge difference in molecules use in these two fields, organic chemistry with all its diversity is definitively the common language that I first acquired during my studies at University of Geneva and that I am still learning today. Recently, in the context of the Merck Serono student program, I had the opportunity to co-direct the $\mathrm{PhD}$ study of Gwénaëlle Desforges in collaboration with Prof. J. Lacour. The $\mathrm{PhD}$ thesis was focused on the synthesis and selective substitution of heterocyclic compounds via aromatic nucleophilic substitution and metal-catalyzed cross-coupling reactions. It was great to create new contacts with the University of Geneva, the place where 
I learned the diversity and the richness of chemistry and the taste for research. It contributed to build a bridge between the academic and the industrial world, where today I am involved as a medicinal chemist. At Merck Serono, I have been utilizing my organic and organometallic chemistry skills to the design and the synthesis of new drugs in the fields of women's health, anti-inflammatory and neurodegenerative diseases, up to clinical phases, a challenging but gratifying mission.

\section{Clémence Corminboeuf, EPFL}

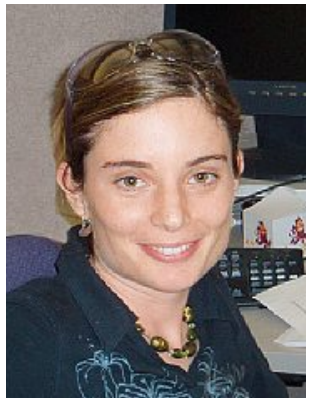

The Pathway of a 'UNIGE' Chemistry Student: The University of Geneva and in particular the Sciences II building became a second home to me in 1996. Prior to becoming a 'UNIGE' chemistry student, I faced two dilemmas, which are not rare for a Geneva student in possession of a scientific (type C) highschool diploma: 1) Do I want to study chemistry or physics? 2) Should I study at the University of Geneva or at EPFL? While I could foresee that physical chemistry could represent a good compromise between chemistry and physics, "chemical physics' was still too abstract to me at this stage. The first decision ended up being straightforward and I finally gave my favours to chemistry. The choice of institute was somewhat trickier and to make up my mind I decided to participate in the on-site visits preceding registration. These visits were determinant: the impressive 20 meter-high distillation columns witnessed during the visit at Monthey organized by EPFL, sharply contrasted with the few milligrams presented in a fundamental research laboratory in Geneva. At that time, the polytechnic school gave a lot of visibility to chemical engineering, to which I was not particularly attracted.

My years as an undergraduate student were really enjoyable and I can say that I was a persistent student attending pretty much every lecture. The first year was a nice refreshment but I found the rest (second year and beyond) of the curriculum pretty heavy. The third year was in particular intense in spectroscopy (physical chemistry III) and organic chemistry (II and III), two fields for which I quickly developed a special interest. The British sense of humour of Prof. Alan Williams along with the vividness of Prof. Claude
Piguet rendered the inorganic chemistry lectures very pleasant and inspiring as well. In contrast, I found myself with less curiosity in analytical and material chemistry, which explains why my knowledge in these domains remained so weak. The introduction to Quantum Chemistry given in 1998 for the last time by the incoming Dean, Prof. Jacques Weber, was certainly decisive for the future direction of my career. Although chemistry is an experimental subject, I quickly realized that I liked much more analyzing data and resolving problems than spending my afternoons in the student laboratory doing wet chemistry. Quantum chemistry gives us the opportunity to understand the concepts on which chemistry is built without having to do 'the cooking'; nothing could have been more appealing to me! For similar reasons, I enjoyed the third-year spectroscopy course given jointly by Profs. Andreas Hauser and Michel Geoffroy. The course aims to discuss the underlying physical and chemical principles associated with specific chemical properties (spectroscopy) rather than focusing on the analytical instrumentation, which was not my cup of tea. To my surprise perhaps, I was also able to appreciate the radically different way of thinking necessary to succeed in the organic chemistry courses taught by Profs Peter Kündig and Paul Müller. Proposing a retro-synthetic step or a mechanism for a given chemical transformation was highly exciting but the perspective of spending the rest of my life in a wet laboratory quickly drove me away from organic chemistry. While I today have lost most of my previous onpaper organic skills, I continue to admire all my colleagues who possess this logic of chemical synthesis. By the end of my third year, I became fully devoted to theoretical/ computational chemistry and oriented all my master level into that direction.

With the years passing and the contents of the courses turning into more advanced (research-like) topics, I also realized that Faculty members were 'researchers' prior to being 'teachers'. This fundamental aspect of academia was not immediately apparent to me. When I started as a freshman chemistry student, I did not realize that behind each professor, there was an entire research laboratory producing $\mathrm{PhDs}$, competing for outside money, developing novel methodologies and concepts, seeking and striving for innovative results, publishing in international peer-review journals, etc. The realization that academia was a challenging field requiring persistence and self-motivation coupled with the excitement of potentially formulating theories leading to paradigm-shifting ways of thinking about chemistry persuaded me to become a scholar. With this certitude in mind, came the desire to leave the Univer- sity of Geneva and explore other departments. With the support and advice of Jacques Weber, I joined the group of Prof. Dennis Salahub at the Canadian National Research Council for my master thesis. Working in the groups of density functional theory (DFT) believers had a real impact on my actual research: I turned into a DFT proponent rather than an $a b$ initionist. I became interested in chemical trends more than in accuracy, which still applies to my research today. After completing my time in Canada, I returned to the University of Geneva to pursue my $\mathrm{PhD}$ in the group of Jacques Weber. This decision enabled me to work independently and I was always encouraged to pursue my own scientific ideas. Since Jacques was not only my $\mathrm{PhD}$ advisor, but also the Dean of the College of Sciences, I also learned a great deal about the politics of academia, which prompted me to think ahead about my scientific future. As a result of this freedom and welcome advice, I spent a lot of time visiting other laboratories such as that of Gotthard Seifert in Dresden, I started to collaborate abroad and quickly got in touch with Prof. Paul Schleyer who first rejected one of my papers proposing an improved version of his dissected nucleus-independent chemical shift. The paper that was finally accepted, initiated my fruitful collaboration with Paul, who almost became a family member and certainly an academic dad (I married one of his $\mathrm{PhD}$ students). When I left Geneva for the University of Georgia in 2004, I knew that the move was definitive as coming back would have been incompatible with my career goal. I left completely focused on research, without ever thinking that I would, one day, settle down 60 kilometres away at the EPFL. Unexpectedly, the Department of Chemistry of the University of Geneva remains a part of my life today: my husband is now working in the same Sciences II building that I occupied several years ago.

Today, I am grateful that I chose to spend my formative scientific years at the University of Geneva, where I was both inspired and prepared for an academic career in chemistry. I found strength to follow the exciting but convoluted academic road because of the background, advices, and encouragements I received during my time there. 


\section{Kelly Velonia, University of Crete}

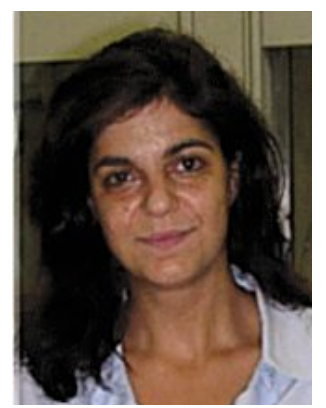

Transition to 'Scientific Independence': After graduating in chemistry at the University of Crete, I carried out a doctoral thesis in the same department under the supervision of Assoc. Prof. I.

Smonou and Prof. G. J. Karabatsos. While studying the mechanisms of action of alcohol dehydrogenases, I placed special focus on the synthesis and selectivity of the dehydrogenase-catalyzed oxidation of partially deuterated propanol. This tiny molecule had a big effect on my decision to join the group of Professor $R$. J. M. Nolte as a post-doctoral fellow! A choice that was not only based on my enthusiasm for the impressive research on supramolecular chemistry carried out in Nijmegen, but was also influenced by the challenge of Giant Amphiphiles. These novel giant soaps ${ }^{[1]}$ would not face problems such as evaporation or separation, I would be able to tackle the synthesis fast and focus on applications! Well, it was not until I started the research that I realized the challenge of working at a totally different scale, the scale of assemblies. And it was this challenge together with the multidisciplinary environment of the Nolte group that allowed me to learn and interact with many disciplines and finally work on projects even more tempting and exciting such as the single enzyme experiments which were carried out in collaboration with Prof. $F$. $C$. De Schryver.

During these first years as $\mathrm{PhD}$ students and later post-docs we are trained in chemistry, laboratory skills and techniques, writing, hopefully creative thinking, and if we are lucky - communication. When the time comes to start our independent career, it is usually excitement that fosters this new professional experience. What we do not realize, but becomes clear in retrospect, is that this excitement could fast fade away. After reaching a new basis, bureaucracy is usually the first enemy. Finding an apartment (I don't know if I ever thanked enough Joy Kündig and Prof. E. Peter Kündig for their hospitality when I reached Geneva in the middle of the night with a fully loaded Twingo that had to be left in their garden for months) and figuring out how to obtain the work permit probably makes you think you have solved the most important obstacle between you and your scientific dreams. Well, this is until you sit down in your brand new office for the first time, define your very ambitious goals and realize that you have no students and no idea how to attract good ones. Of course you also have little experience on how to train them, make them productive, or deal with communication problems that are bound to occur, but this is something you realize much later. Science comes first, and you are probably pretty sure at the time that you can run it all by yourself. You soon realize that you are totally clueless as to how much acetone costs or how high (or low in my case) will be the survival rate of NMR tubes in the hands of you and your prospective students. You are also oblivious as to the quantities of chemicals a lab needs or how to even order it as you have always had all the necessary equipment ready and set for you to focus on research. Planning and economics can easily bring a crisis, no matter how lucky you are with the startup funds or with attracting scientific programmes. Such practicalities are perhaps the most trivial impediments for someone starting his independent career in a university away from 'home'. There is so much that we can never be trained enough for... Nevertheless, it is 'scientific isolation' that can be the biggest enemy. If someone is as lucky, as I have been, to have previously worked in vivid and stimulating multidisciplinary scientific environments that promote discussions and collaboration as the basis for problem solving or developing novel ideas (and for this I will always be grateful to Prof. R. J. M. Nolte), the new reality of the two-people-maximum group meetings can be intimidating ...

Having said all this, I am indebted to the Department of Organic Chemistry of the University of Geneva and all my colleagues there, if not for anything else, for providing a scientific and social environment that fed my enthusiasm and excitement about chemistry itself vivid throughout my stay there.

The Department of Organic Chemistry of the University of Geneva enjoys international recognition for excellence in both research and teaching. I have to admit that my excitement for the opportunity given to me to work there as Maître Assistante in 2004 was accompanied with the apprehension of being able to stand up to the standards and fulfil both my responsibilities and scientific goals. In retrospect, I shouldn't have been as anxious as the tradition of the Department is based on a well organized and exceptionally conscientious scientific environment, which is probably what makes it one of the biggest schools for a new academic. When I arrived there, my lab was renovated, clean and, more importantly, there was someone there who knew all there is to know about the practicalities of running a laboratory (and so much more). The technicians that have worked in my laboratory (Patricia Millason Schmidt and David Gerard) have been invaluable in both maintaining the lab and science. My responsibilities and teaching load were set, clear and organized well in advance. More importantly, my colleagues, while being discrete and respecting my new independence, made it obvious that I could always ask for advice which they graciously offered no matter how busy their schedules were. Their experience helped find and select students, reposition my focus from time to time and avoid or solve from trivial to more serious problems. One separate attribute that characterizes this department is that scientific isolation is not an option! Starting from the sincere interest on the progress of one's research and going all the way to the intra-laboratory support and collaborations, the international character, the very organized lecture programme and even the interaction during the coffee breaks (which kept my Greek in shape and taught me so much thanks to Prof. Alexakis). In addition to all these, I had the luck to be welcomed together with my students by Prof. Stefan Matile in his group meetings (and - equally important - in many of their social meetings). These meetings were characterized by the multidisciplinary scientific environment and discussions that are essential in training both students and PIs.

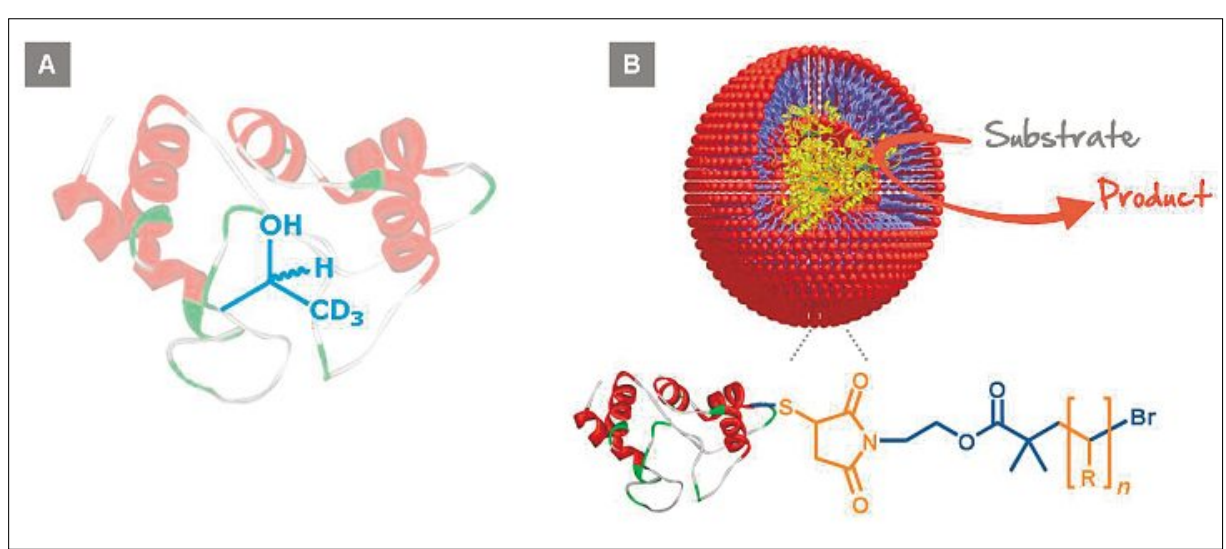

Fig. 1. (A) Partially deuterated 2-propanol synthesized to study the limits of ADH stereoselectivity. (B) General scheme of the protein-polymer biohybrid nanoreactors developed in Geneva. ${ }^{[3,4]}$ 
Making use of all this support system, while being in Geneva my main focus was placed on the construction of multifunctional biohybrid nanoreactors. The goal was to develop the means that allow the efficient synthesis of well defined, amphiphilic, protein-polymer biohybrids using simple chemical approaches. A successful synthetic approach would make the supramolecular assemblies of these Giant Amphiphiles more accessible and allow for them to be studied with regard to their full application potential.[2] Having worked on the first Giant Amphiphiles while being in the Nolte group, ${ }^{[1]}$ I recognized the difficulties of this particular system and acknowledged that its realization entailed multidisciplinary training of students and fresh ideas. The facilities, organization and support of the department together with the dedication of a talented student (Benjamin Le Droumaguet) were crucial parameters for the success of the project. During my stay in Geneva, we accomplished the synthesis and full characterization of new families of such biohybrids in excellent yields and were able to create and study their supramolecular multifunctional nanoreactors (Fig. 1). ${ }^{[3-5]}$ These studies and the collaborations developed while in $\mathrm{Ge}$ neva have served as a strong basis for the research performed in my current position as an Assistant Professor in the Materials Science and Technology Department of the University of Crete. My hope is that along with the gratitude for this experience and the scientific knowledge, I also carry with me the scientific mentality of my colleagues in Geneva that helped me through this first transition to 'scientific independence'.

[1] P. Thordarson, B. Le Droumaguet, K. Velonia, Appl. Microbiol. Biotechnol. 2006, 73, 243.

[2] K. Velonia, A. E. Rowan, R. J. M. Nolte, J. Am. Chem. Soc. 2002, 124, 4224.

[3] B. Le Droumaguet, G. Mantovani, D. M Haddleton, K. Velonia, J. Mater. Chem. 2007, 17, 1916.

[4] B. Le Droumaguet, K. Velonia, Angew. Chem. Int. Ed. 2008, 47, 6263.

[5] B. Le Droumaguet, K. Velonia, Macromol. Rapid Commun. 2008, 29, 1073.

\section{Kevin Wilkinson, University of Montreal, Canada}

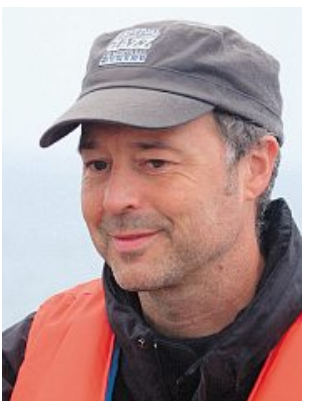

Discovering 'Molecular' Environmental Chemistry

A question of scale: The vast majority of environmental chemists work on spatial scales ranging from a meter to several hundreds of kilometres, evaluating for example trace metal mobility on the scale of a watershed or the global transport of organic contaminants. I first became interested in working on micro- and nano-scale environmental chemistry while working as a graduate student with Peter Campbell at INRSEau (National Water Research Institute, University of Québec, Canada). At the time, we were interested in relating chemical speciation to bioavailability. ${ }^{[1]}$ It was after reading a seminal paper that treated trace metal uptake from an electrochemical perspective $^{[2]}$ that I became fascinated by the microor nano-scale reactions that were required to fully understand macro-scale environmental processes. In looking for a post-doctoral fellowship that could advance my knowledge of 'molecular' environmental chemistry, I learned of the work of Prof. Jacques Buffle (University of Geneva), who had also spent some time at INRS-Eau. Although our paths had never crossed, he was certainly held in very high esteem throughout the Institute. I sent Jacques an e-mail and he telephoned me the following day with the offer of a postdoctoral fellowship. I remember little of my arrival in Geneva several months later, except of course, the warm reception and the fact that I hadn't slept for 48 hours. In spite of my sleep deprivation, Jacques was enthusiastic in showing me around the lab and having me meet his (extensive) group. In spite of my excitement for the new position, I was most interested in staying awake and finding a shower.

Following the post-doctoral fellowship, Jacques encouraged me to remain in Geneva, while providing me with increasing scientific independence. In fact, I have no doubt that my internship was a good reflection of what was hoped for by those who had developed the somewhat unique Swiss system of junior faculty positions. Following a post-doctoral fellowship of 18 months, I was given more responsibilities (but no budget) as a Maître-assistant (junior lecturer). Shortly thereafter, I began developing my own research directions, acquiring my own funds and was promoted to Maître d'enseignement et de recherche (senior lecturer). In those early years, I felt extremely privileged to have an unimpeded access to state-of-the-art analytical equipment and superb mentoring from Jacques. Looking back now with new perspective gained from the University of Montreal, I feel very fortunate to have passed these early years in Swiss system of mentoring in contrast to the North American version of 'sink or swim'. Nonetheless, much of the credit goes to Jacques for his deep comprehension of the scientific problems that we were working on and for his encouragement that I develop my own directions.

Research directions: The research that I am currently interested in is the logical continuation of my training in both Geneva and Quebec. For example, we are still very interested in gaining a molecular level understanding of contaminant bioavailability and mobility. One goal is thus to identify some of the mechanistic limitations of the bioavailability models, ${ }^{[3]}$ which often requires that we develop novel analytical techniques to quantify trace metal speciation ${ }^{[4]}$ or bioavailability. ${ }^{[5]}$ Indeed, early in my tenure in $C A B E$ (Biophysical and analytical Environmental Chemistry Group, University of Geneva), I naively thought I could spend a summer testing the numerous speciation techniques in the group in order to select the best one for bioavailability measurements. Fifteen years later, we are still attempting to better understand bioavailability and develop both biosensors and chemical sensors to quantify trace metal uptake and effects. Additionally, knowledge gained during work at the University of Geneva on colloidal transport, is currently being used within projects that relate the structure of (nano)particles and their aggregates to their mobility and bioavailability. ${ }^{[6]}$ As was the case in $C A B E$, current work includes an important analytical component including state-of-the-art analytical characterisation (e.g. fluorescence correlation spectroscopy, nanoparticle tracking analysis) and highly specific biological effects measurements (e.g. gene/polypeptide induction using RT-QPCR, LC-MS). Recent projects are also examining the role of molecular diffusion in (environmental and medical) biofilms and flocs and developing whole cell biosensors for novel contaminants.

What did I really learn? In addition to the large quantity of internationally recognized science, in my opinion, the most important thing that I learned at the University of Geneva was to first identify the environmental problem, process or structure of interest. Once the problem was clear (and hypotheses had been elucidated), then it was important to determine what were the best parameters to measure in order to get maximum insight into the problem. Finally, we would determine what was the best analytical technique to quantify the parameters of interest. In $C A B E$, this often lead to the development of a new sensor or new analyti- 
cal method. Another point that was driven home during my studies was the importance of the existing literature. I can never hope to be as well read as either Campbell or Buffle. At INRS, Peter had an amazing grasp of the literature - his most common response to a question was "Have you read the paper by $\mathrm{x}$ that corresponds to reference no. 3495 in my Refman database". During the first five years of my collaboration with Jacques, nearly every question that I had led to me reading a section of his comprehensive textbook. ${ }^{[7]}$ Although that book is now out of print, the last time that I verified, a used copy was for sale on Amazon for 3600 \$!

Acknowledgements: A final note: it is essential to mention that I wouldn't be in a position to write this paper without the work and collaboration of those around me - first in the teams of my mentors Peter Campbell and Jacques Buffle and subsequently in my own groups. Unfortunately, it is impossible to mention all those involved and only possible to give a couple of examples. In $C A B E$, Jacques was always very careful to define the important problems that he wanted to solve and then put in place a multidisciplinary team that could work together on the different aspects. For example, modellers/ theoreticians would identify the working hypothesis (e.g. S. Stoll and H. P. van Leeuwen), a sensor would be developed to make the key measurements (e.g. M. L. Tercier, $N$. Parthasarathy and F. Bujard), a experimental team (e.g. K. J. Wilkinson, D. Perret, $R$. DeVitre) would test the hypothesis only to lead to further model development and refinements of the sensor/hypothesis, etc. I strive to attain a similar synergism in my groups and have been fortunate to have been able to recruit a large number of excellent researchers and students, several of whom are currently Faculty at other Universities and research institutes (e.g. E. Balnois, J. R. Lead, V. Slaveykova, C. S. Hassler, R. F. Domingos). I hope to further emulate these colleagues and others and continue learning from my students during the next half of my career.

[1] K. J. Wilkinson, P. G. C. Campbell, P. Couture, Can. J. Fish. Aquat. Sci. 1990, 47, 1446.

[2] M. Whitfield, D. R. Turner, in 'Chemical Modelling in Aqueous Systems', Ed. E. A. Jenne, ACS Symposium Series, Vol. 93, American Chemical Society, Washington DC, 1979, pp. 657-680.

[3] V. I. Slaveykova, K. J. Wilkinson, Environ. Chem. 2005, 2, 9 .

[4] I. A. M. Worms, K. J. Wilkinson, Analyt. Chim. Acta. 2008, 61, 95.

[5] D. F. Simon, P. Descombes, W. Zerges, K. J. Wilkinson, Environ. Toxicol. Chem. 2008, 27, 1668.

[6] R. F. Domingos, N. Tufenkji, K. J. Wilkinson, Environ. Sci. Technol. 2009, 43, 1282.

[7] J. Buffle, 'Complexation Reactions in Aquatic Systems: An Analytical Approach', Ellis Horwood, Chichester, 1988.

\section{Frank Kubel, TU Wien}

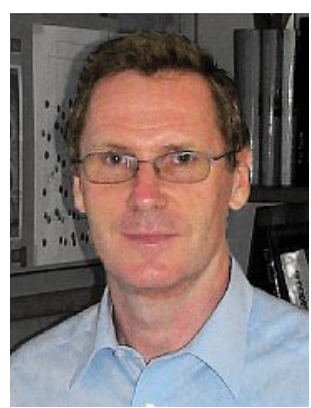

Order and Disorder in Geneva: Crystal structures and structural chemistry of disordered samples. Thinking about the University of $\mathrm{Ge}$ neva allows me to reflect on a scientific career devoted

to disorder in solids. As an extension to the Swiss laws, I could spend more than 14 years at the University and had the opportunity to work in three scientific groups. During this period of my life, I learned a lot about Swiss culture and the serious approach to science. Swiss people are perfectly organized and dislike lack of order. So the study of disordered systems became my topic in Geneva. Shortly after finishing my thesis, Prof. Yvon invited me 1984 to join his group at the Laboratoire Interdisciplinaire de Cristallographie aux Rayons X. Single crystal structure analysis of superconducting compounds was the main subject; one highlight was the electron density study of almost stoichiometric VN. Defects play an important role in this group of compounds,

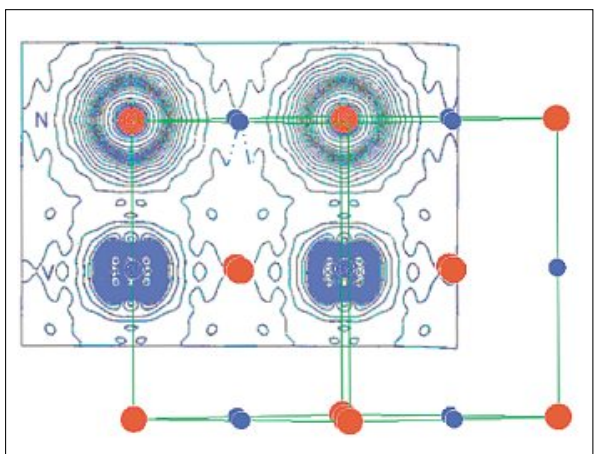

Fig. 1. Electron density distribution in $\mathrm{NaCl}$ type almost stoichiometric vanadium nitride. ${ }^{[1]}$ and my task was the study of an almost stoichiometric specimen. Vanadium nitride was prepared at the TU Vienna (where I was later appointed) and was analyzed in detail. The programming skills of Howard Flack allowed an electron density refinement of orbital populations (Fig. 1 in $1-10$ projection) and to predict a low temperature phase transition. Only a small amount of defects was observed $\mathrm{VN}_{0.9986(8)}$, so the disorder was relatively low compared to $\mathrm{TiN}_{0.99}$ and $\mathrm{TiC}_{0.94}$ studied before by Prof. Yvon. Theoretical calculations were made at the Technical University of Vienna by Karlheinz Schwarz and showed a perfect match of the data.

In 1988, Prof. Hans Schmid (head of the Laboratoire de Chimie minérale et appliquée) invited me to analyze the crystal structures of his compounds. At that time I did not realize that all of his crystals were heavily twinned. Getting rid of ferroelastic domains was one of the important exercises to obtain refineable crystals. Disorder by domains gives beautiful crystal photos in polarized light but order helps to understand the properties. Some of his boracite crystals had to be switched with pressure using pincers and a lot of strength. Highlight during this research period was the synthesis and structure of $\mathrm{BiFeO}_{3}$ as well as the creation of selected ferroelectric and ferroelastic domains by switching with mechanical pressure or electric fields. ${ }^{[2]}$ Atomic displacements could so be understood (see Fig. 2). Up to now this paper is one of my most cited publications ( 250 in 2009).

These structures together with other structures from mechanically detwinned crystal have been the basis of a habilitation thesis entitled 'Structural studies of compounds in relation with a phase transition', which I completed in 1992. When Prof. Schmid retired, Prof. Bill (head of the Département de Chimie Physique) asked me to join his group. Together with

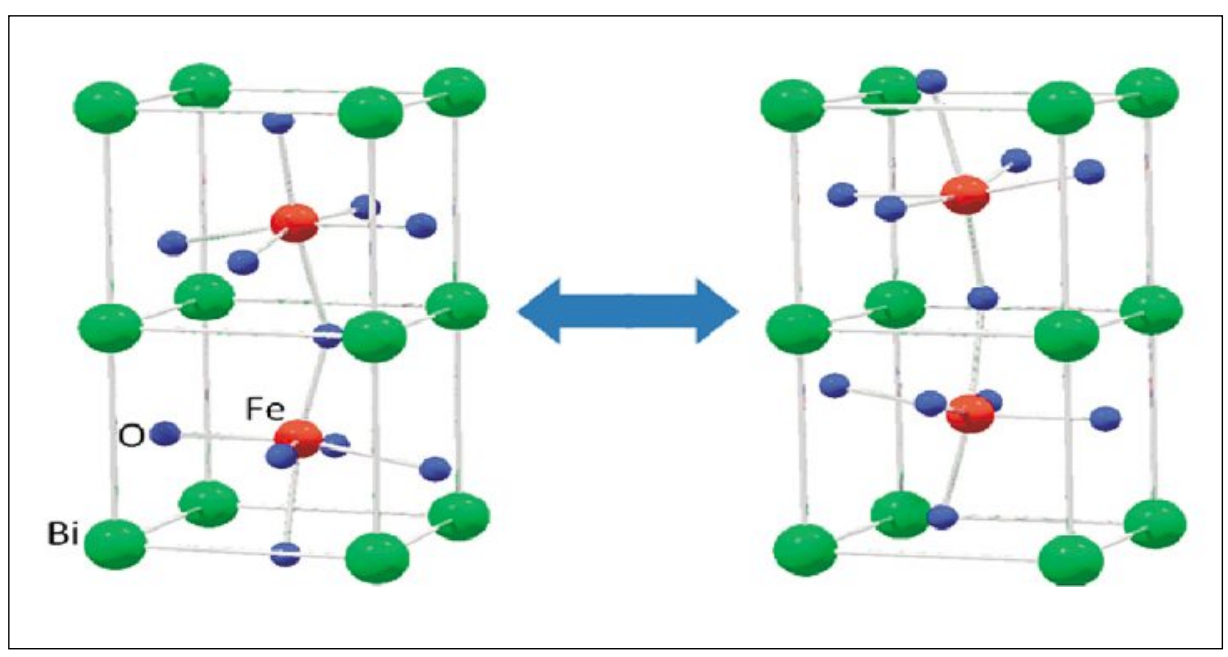

Fig. 2. Ferroelectric switching in $\mathrm{BiFeO}_{3}{ }^{\left[{ }^{[2]}\right.}$ 


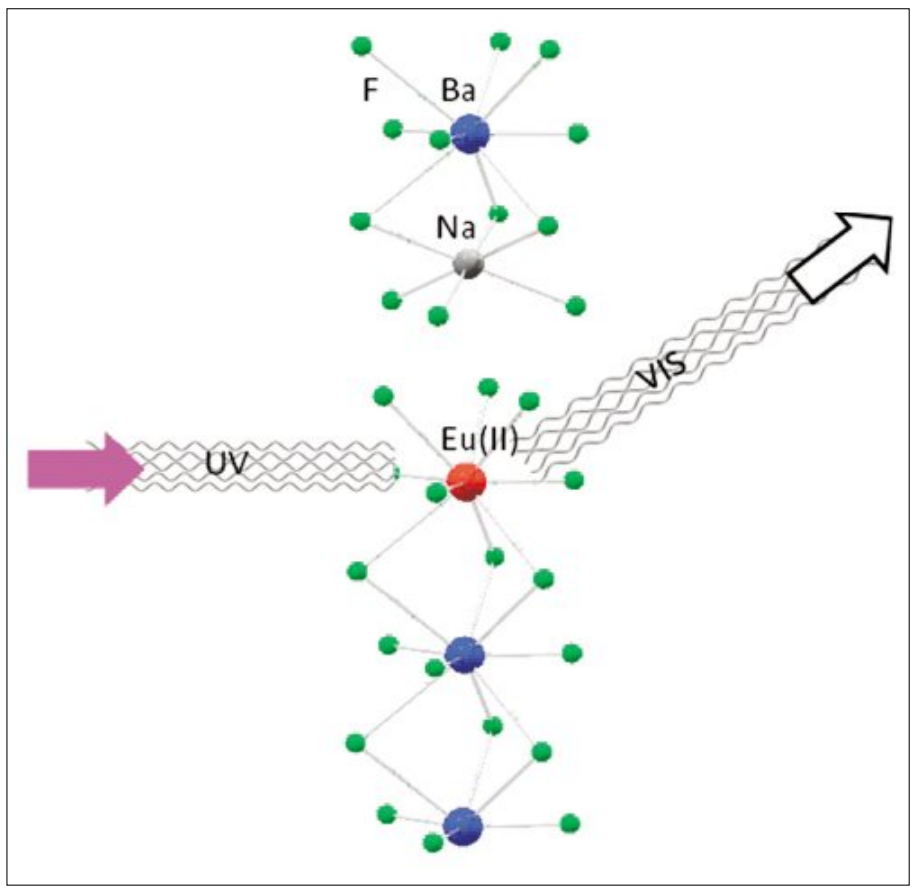

Fig. 3. $\mathrm{Ba}_{7} \mathrm{~F}_{12} \mathrm{Cl}_{2}$ doped with divalent europium as brilliant white phosphor. ${ }^{[3]}$

Dr. Hans Hagemann, the synthesis and structural characterization of new host matrices for rare earth compounds was the main research subject. Highlight was the synthesis and structural analysis of $\mathrm{Eu}(\mathrm{II})$ doped $\mathrm{Ba}_{7} \mathrm{~F}_{12} \mathrm{Cl}_{2}$, a highly intense white phosphor. Prof. Bill decided to patent this compound, which is one of the worldwide rare single compound phosphors emitting intense white light under UV. Later the deeper structural analysis revealed the reason for this property: the active element is located in a channel occupied with different atoms, $\mathrm{Ba}$ (II), $\mathrm{Na}$ (I) and $\mathrm{Eu}$ (III) (see Fig. 3) creating a strong variation of the energy conversion related to variations in the crystal field.

In 1998, I left Geneva and accepted a post as Professor of the Technical University of Vienna. My Institut für Mineralo- gie, Kristallographie und Strukturchemie allowed me to continue a research on disordered compounds and phosphors. The intense collaboration and friendship to Hans Hagemann was continued after my departure from Geneva. Several publications and regular mutual scientific visits show the fruitful link established between the universities of two alpine countries.

"Two dangers constantly threaten the world: order and disorder", Paul Valery (1871-1945).

[1] F. Kubel, H. D. Flack, K. Yvon, Phys. Rev. B 1987, 36, 1415 .

[2] F. Kubel, H. Schmid, Acta Cryst. B 1990, 46, 698.

[3] F. Kubel, M. Bill, H. Hagemann, Z. anorg. allg. Chem. 1999, 625, 643 . 